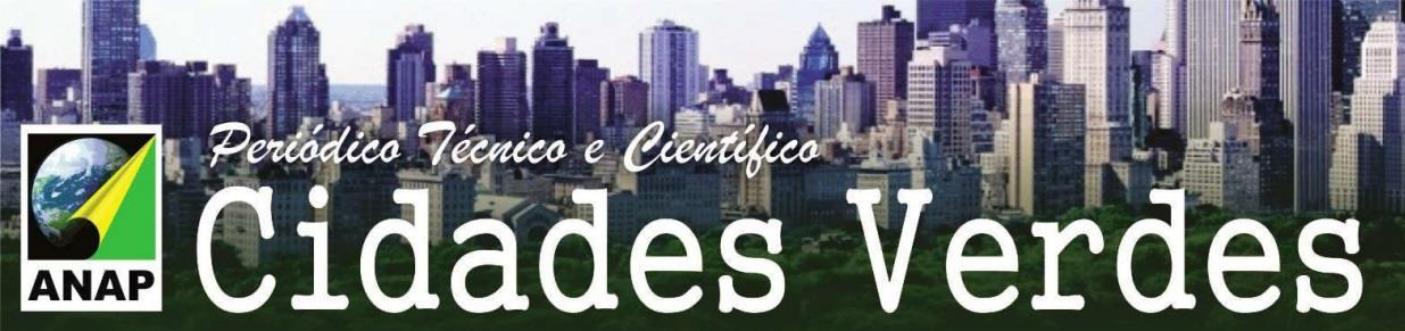

\title{
AGENDA 21 DE VOLTA REDONDA: UMA EXPERIÊNCIA A SER CONTADA
}

Leticia Barroso ${ }^{1}$

\author{
Vera L. Rezende ${ }^{2}$
}

\section{RESUMO}

Este trabalho visa apresentar a experiência da Agenda 21 Local, um processo, entre os períodos de 1997 a 2007, na cidade de Volta Redonda, construída para abrigar a Companhia Siderúrgica Nacional-CSN, o estratégico empreendimento do Governo de Getúlio Vargas com o objetivo de ampliar o desenvolvimento da economia brasileira. A relação entre a empresa e a cidade permaneceu por muitas décadas até a privatização da CSN, que trouxe graves problemas socioeconômicos. A Agenda 21 naquela época representou a possibilidade da construção de um novo padrão de desenvolvimento na cidade. A partir das recomendações da Agenda 21, e com foco na sustentabilidade, foi criado em 2000 o Fórum local constituído por diversas entidades da cidade, e a partir de encontros, seminários, diagnósticos da realidade local, propostas foram apontadas, que resultaram no documento denominado Plano de Ação de Volta Redonda. O processo contribuiu para a inserção das recomendações da Agenda 21 no Plano Diretor, como também, a inclusão de Programas no Orçamento Municipal. Assim, este processo introduziu uma nova forma de diálogo entre governo e a sociedade civil.

PALAVRAS-CHAVE: sustentabilidade, Agenda 21, participação.

\section{INTRODUÇÃO}

O crescimento econômico foi sempre considerado como algo ilimitado e importante para o desenvolvimento das cidades e a redução das desigualdades sociais. Mas, esta visão vem sendo questionada desde a década de 1970, quando foi realizada a primeira Conferência de Meio Ambiente em 1972 em Estocolmo.

\footnotetext{
${ }^{1}$ Universidade Federal Fluminense - UFF. E-mail leticiabarroso@gmail.com

${ }^{2}$ Universidade Federal Fluminense - UFF. E-mail vrezende1234@gmail.com
} 


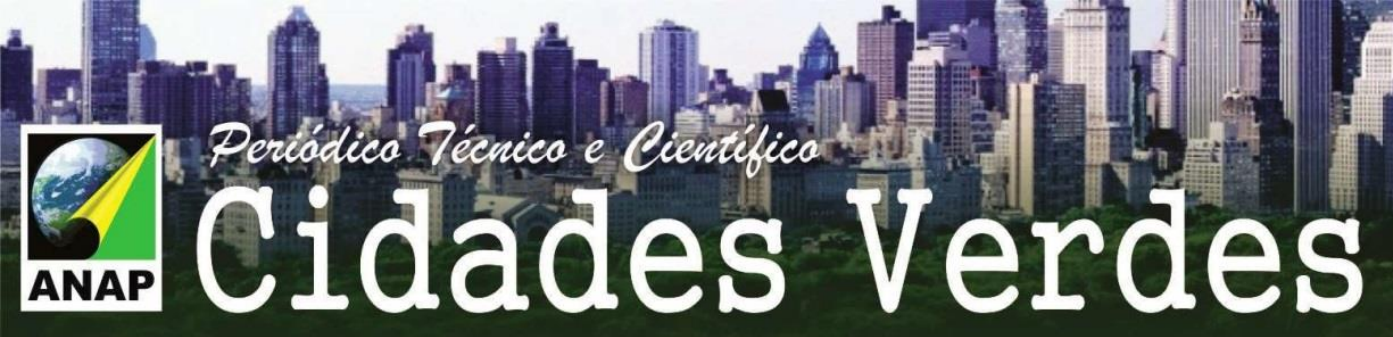

Este artigo trata da instalação da Agenda 21 em Volta Redonda, Estado do Rio de Janeiro. A cidade de Volta Redonda foi criada na década de 1940 e tinha como propósito não só alavancar a economia brasileira como também o de constituir um trabalhador modelo. O governo de Getúlio Vargas foi "marcado, na história do Brasil, por um profundo e conflituoso esforço de construção de um projeto de nacionalidade sob a firme promoção do Estado."(LOPES,2003,p.25)

Diferente de outros lugares, não se tratava de uma vila operária, mas sim uma cidade que abrigaria uma população de 20.000 habitantes, planejada nos moldes de uma cidade industrial, sendo a primeira do país. Assim, foram construídos outros equipamentos tais como: hospital, posto de saúde, escola, cinema, praças, ginásio esportivo e moradias.

Figura 1 - Plano geral da cidade e da Vila Operária

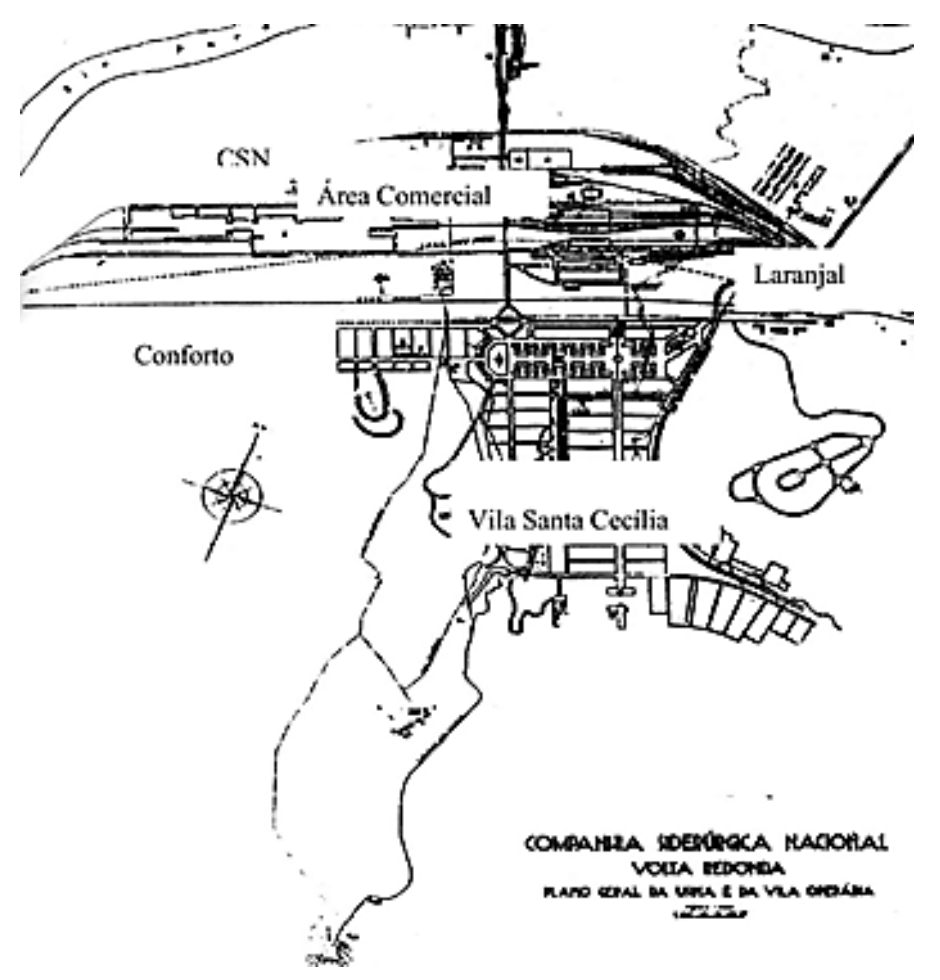

Fonte: SOUZA,1992,p.65 
Em 1997, em Volta Redonda, iniciou-se a mobilização dos diversos segmentos da sociedade local no sentido de repensar a cidade diante da crise socioeconômica que a cidade atravessava naquele momento. Nesta época, foi proposta pela sociedade a instalação da Agenda 21, uma metodologia capaz de mobilizar a população para enfrentar os problemas diante da privatização da CSN, em 1993, diante do processo de demissões maciças na empresa e com a falta de um projeto de desenvolvimento alternativo que apontasse o futuro com qualidade de vida.

\section{OBJETIVOS}

- Apresentar e discutir o processo da Agenda 21 da cidade de Volta Redonda instalado em 1997.

\section{METODOLOGIA}

Para dar inicio foi, então, criada a comissão Pró-Fórum da Agenda 21, constituída por representantes da sociedade civil e do governo municipal com a finalidade de mobilizar a sociedade local e implantar Fórum Local. Para este momento, foram realizados diversos encontros com aproximadamente oitenta entidades da cidade, entre elas, ong's, associações de classe, sindicatos, universidades, associação comercial, entre outas, apresentando os princípios da Agenda 21 de forma a sensibilizá-los para a participação na Agenda 21 Local.

O Io Encontro de Planejamento da Agenda 21 foi realizado em maio de 1998, quando então, foi traçada uma visão de futuro compartilhada, com a presença de 30 entidades da sociedade civil, além de representações públicas. No evento, os representantes das entidades formularam alguns desejos de uma Volta Redonda sustentável. 


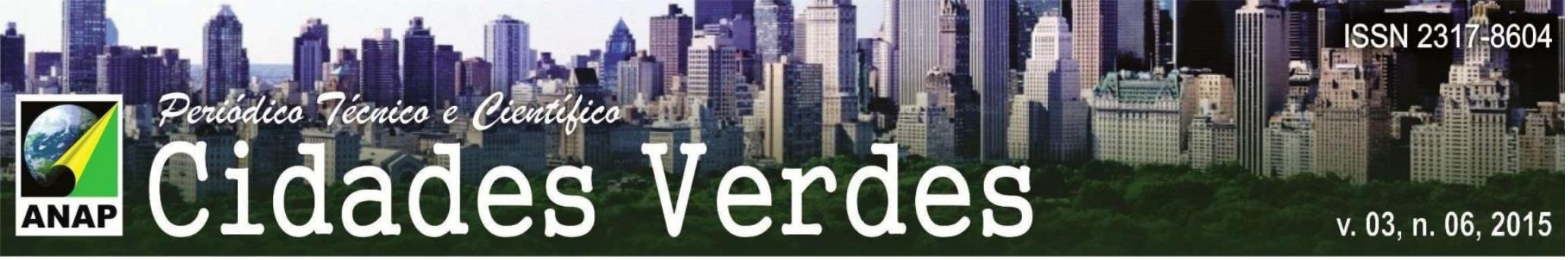

Foto 1- Io Encontro de Planejamento da Agenda 21

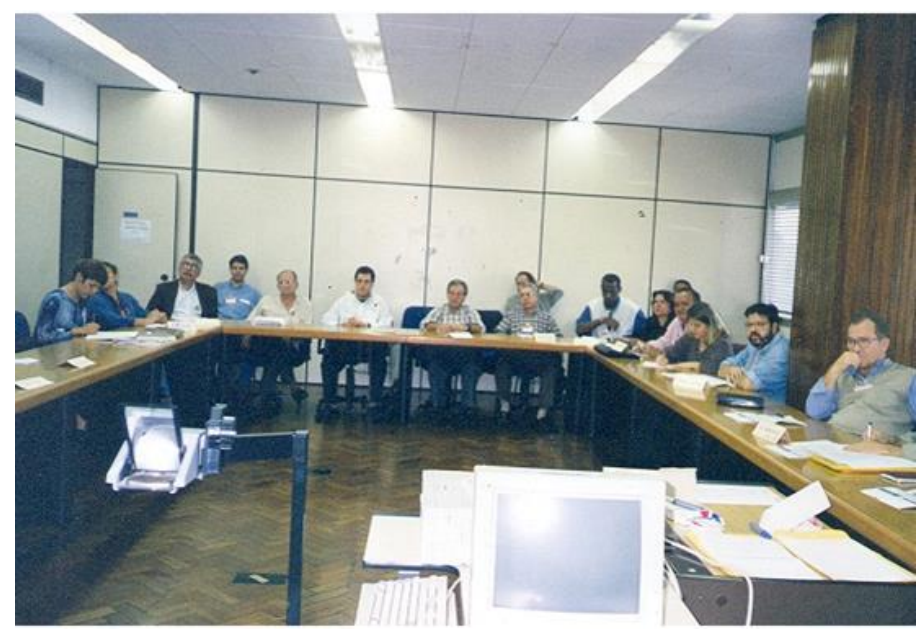

Fonte: Assessoria de Comunicação Social da Prefeitura de Volta Redonda

A partir de então, foram criados Grupos Temáticos, num total de sete que passaram a reunir-se periodicamente, com o propósito de aprofundar os problemas da realidade local e apontar ações, sendo eles: poluição atmosférica, recursos hídricos, lixo, arborização urbana, trabalho e renda, educação e cultura e por último, as questões relacionadas à criança e ao adolescente.

Cada Grupo Temático (GT) contava com um Coordenador, que compunha o Grupo Gestor, Grupo este constituído pelos coordenadores dos GTs com a finalidade de reunir todas as informações, debates, reflexões e encaminhamentos realizados nos Grupos Temáticos. Os Grupos Temáticos se reuniam quinzenalmente. Inicialmente foi realizada uma aproximação com o tema por todos os integrantes e posteriormente 0 diagnóstico seguido dos encaminhamentos/propostas/campanhas. Bimestralmente foram realizadas as Reuniões de Integração, com a participação de todos os integrantes dos Grupos Temáticos para apresentar o desenvolvimento dos debates de recomendações dos GTs. 


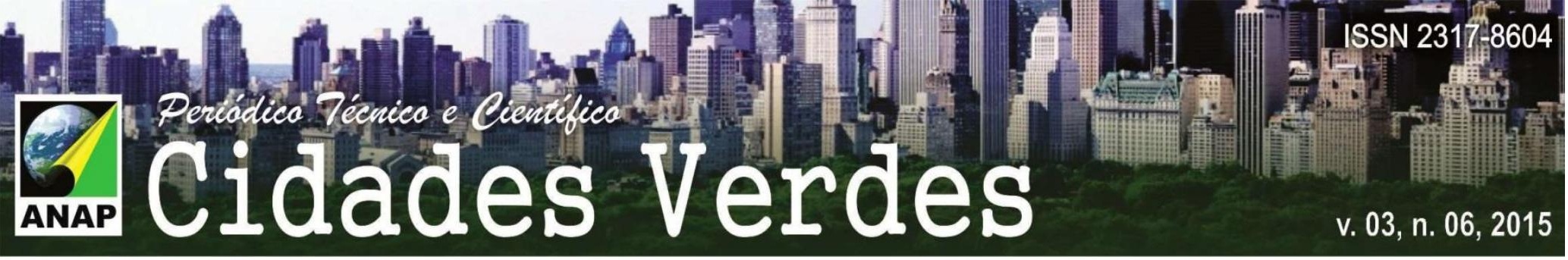

Figura 2- Esquema do funcionamento da Agenda 21

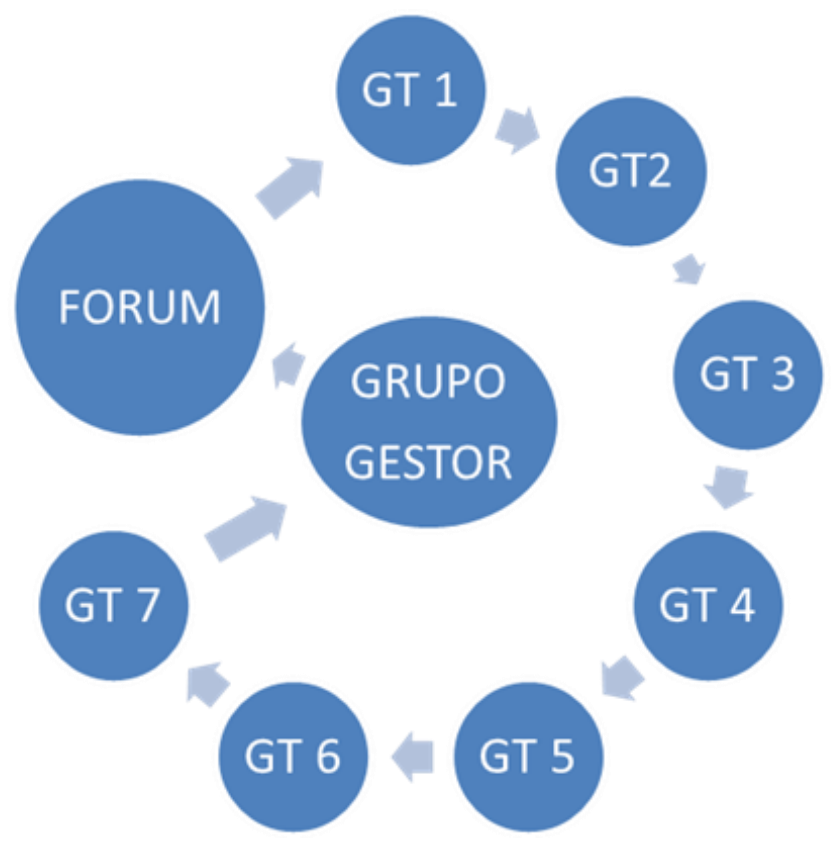

Fonte: Elaborado pela autora

\section{MÉTODO DE ANÁLISE}

O método adotado na pesquisa para a análise deste processo foi a da Observação Participante. Este método foi adotado por se tratar de uma técnica em que há possibilidade de não só observar como também integrar e participar das atividades, ou seja, ocupar o papel do observador no grupo, ou o ambiente pesquisado. Considerando a participação de diversos atores sociais foram utilizadas entrevistas semi-abertas visando buscar as expectativas, os motivos e as dificuldades na construção do processo. Em complementariedade, contou-se com informações em fontes primárias disponíveis na Agenda 21 de Volta Redonda, tais como, atas das reuniões, reportagens em jornais locais, entre outras. Foram analisados os orçamentos e o Plano Plurianual da Prefeitura de Volta Redonda. 


\section{RESULTADOS}

A pesquisa apontou que a Agenda 21 cumpriu um papel importante, na medida em que, a sociedade local poderia contar com um espaço para expressar e debater novas possibilidades, frente a uma crise vivenciada pela cidade, pósprocesso de privatização da CSN. Nesse sentido, este processo promoveu a integração das entidades na formulação de um projeto, menção constante nas assertivas dos entrevistados, tais como, pensar uma cidade, colaborar para uma melhor qualidade de vida.

Cabe destacar, que as recomendações da Agenda 21 formuladas pelos Grupos Temáticos, em sua maioria tratavam das questões de cunho ambiental. Das recomendações propostas pela Agenda 21, a poluição ambiental tornou-se uma questão central, o que justifica a inclusão no orçamento do município de algumas propostas relacionadas ao tema.

Um dos desdobramentos da Agenda 21 de Volta Redonda com vistas à sustentabilidade urbana foi a inserção das recomendações no Plano Diretor Participativo de 2006, a inclusão no Plano Plurianual 2001-2205 de propostas referentes ao monitoramento da qualidade do ar e a previsão de investimentos em monitoramento ambiental no Orçamento municipal.

\section{CONCLUSÃO}

A história da cidade revela que a sociedade experimentou tanto os sentimentos de uma cidade criada para ser o símbolo do progresso nacional como também os reflexos da privatização da CSN e seus impactos. Assim, identificamos nesta cidade os conflitos entre a natureza e o ambiente construído, capital e trabalho, Estado e sociedade.

Com base na pesquisa, desafios e possibilidades devem ser destacados durante o processo da Agenda 21 Local. Para o desenvolvimento da Agenda 21 é fundamental a participação. Mas as dificuldades relativas à participação, tanto do 


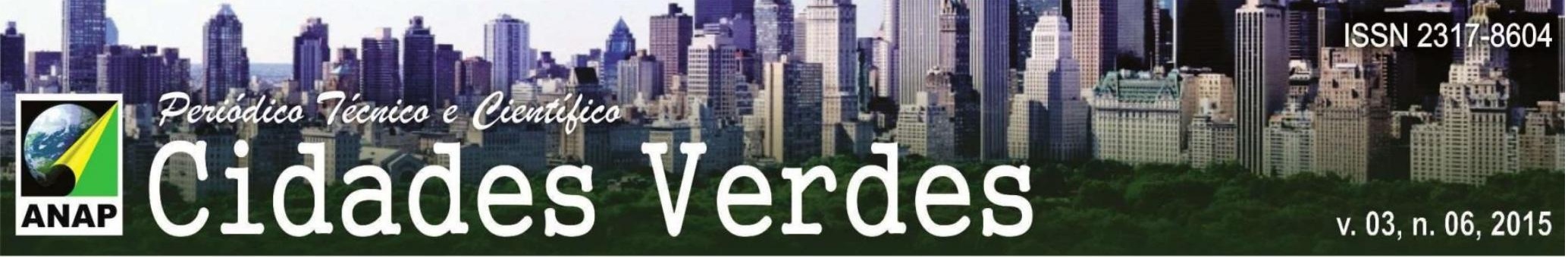

Executivo, quanto do Legislativo, e também da sociedade civil, provavelmente se deve à falta de prática no compartilhamento de decisões.

Quanto às possibilidades, o diálogo entre o Estado e sociedade possibilitou o aprendizado de uma prática participativa apesar das limitações. Diante destas questões conclui-se que as perspectivas para o futuro da sociedade local para uma cidade sustentável, deverá ser aquela cidade despoluída e provida de uma gestão democrática.

\section{REFERÊNCIAS}

ACSELRAD, Henri. Conflitos Ambientais no Brasil. Rio de Janeiro: Relume-Dumará: Fundação Heinrich Böll, 2004. 294 p.

Sentidos da sustentablidade urbana. In: A duração das cidades: sustentabilidade e risco nas políticas urbanas. Rio de Janeiro:DP\&A, 2001.240 p. 27-55.

; MELLO, Cecília Campello do Amaral; BEZERRA,Gustavo das Neves. Cidade, Ambiente e Política. Problematizando a Agenda 21 Local. Rio de Janeiro:Garamond, 2006.133p.

BARROSO, Leticia de Souza. Agenda 21: uma experiência em Volta Redonda. Dissertação (Mestrado em Arquitetura e Urbanismo) Universidade Federal Fluminense. Niterói - RJ. 2008.

COMISSÃO MUNDIAL SOBRE O MEIO AMBIENTE E DESENVOLVIMENTO (CMMAD). Nosso Futuro Comum. Rio de Janeiro: Editora da Fundação Getúlio Vargas, 2 ed. 1991. 430 p.

CONFERÊNCIA DAS NAÇÕES UNIDAS SOBRE O MEIO AMBIENTE E DESENVOLVIMENTO. 1992, Rio de Janeiro. Agenda 21.Brasília: Senado Federal, Subsecretaria de Edições Técnicas, 1997. $585 \mathrm{p}$.

CORRÊA, Silvia Borges. O processo ambientalizador e a etiqueta ambiental da empresa que "pensa verde": o caso da Companhia Siderúrgica Nacional. Rio de Janeiro,2006. 178 f. Tese (Doutorado em Ciências Sociais) - Instituto de Filosofia e Ciências Humanas, UERJ, Rio de Janeiro. 2006.

COSTA, Heloisa Soares de Moura. Desenvolvimento Urbano Sustentável: Uma contradição de termos? in Revista Brasileira de Estudos Urbanos e Regionais.Norma Lacerda, n 2, março 2000.5570

HARVEY, David. A Condição Pós-Moderna: Uma pesquisa sobre as Origens da Mudança Cultural.15 ed. São Paulo: Loyola, 2006.

Mundos Urbanos Posibles. Lo Urbano, em 20 autores Contemporâneos. Barcelona:

Ramos Angel Martin. Escola Técnica Superior de Arquitetura de Barcelona, ETSAB, 2004.

HERCULANO, Selene. Em busca da boa sociedade. Niterói: EdUFF, 2006. 426p.

LEFF, Enrique. Ecologia, Capital e Cultura: Racionalidade ambiental, democracia participativa e desenvolvimento sustentável. Blumenau: Ed. da FURB, 2000. 381 p 


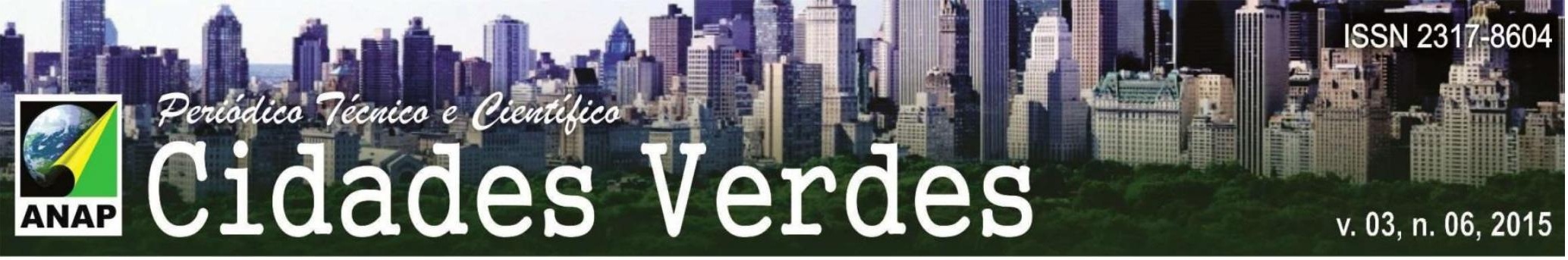

LOPES, Alberto. A Aventura da forma: Urbanismo e Utopia em Volta Redonda. Rio de Janeiro: EPapers Serviços Editoriais, 2003. 188 p.

LOPES, José Sérgio Leite. Conflitos Ambientais no Brasil. In ACSELRAD, Henri (org). A Ambientalização dos Conflitos em Volta Redonda. Rio de Janeiro: Relume-Dumará, 2004. 294 p, p.217-244.

SOUZA, Claudia Virginia Cabral de. Pelo espaço da cidade: Aspectos da vida e do conflito urbano em Volta Redonda. Rio de Janeiro, 1992. 206 f. Dissertação (Mestrado em Planejamento Urbano e Regional) - Instituto de Pesquisa e Planejamento Urbano e Regional, Universidade Federal do Rio de Janeiro, Rio de Janeiro, 1992.

SOUZA. Marcelo Lopes de. Mudar a Cidade. Uma Introdução critica ao Planejamento e à Gestão Urbanos. 4ed.Rio de Janeiro: Bertrand Brasil, 2006.560 p.

STEINBERGER, Marilia. A(re) construção de mitos. Sobre a (in)sustentabilidade (no) espaço urbano. Revista Brasileira de Estudos Urbanos e Regionais. Associação Nacional de PósGraduação em Pesquisa em Planejamento Urbano e Regional n. 4, p. 9-32, maio, 2001

WIRTH, John D. A Política do Desenvolvimento na Era de Vargas. Rio de Janeiro: Fundação Getúlio Vargas.1973. p. 20. 